\title{
Avowals and the project of inferentialism
}

\author{
Bastian Reichardt ${ }^{1}$
}

(C) The Author(s) 2020, corrected publication 2021

\begin{abstract}
Whether there are philosophically relevant connections between the expressive role of first-personal vocabulary and self-knowledge is an on-going debate in analytical philosophy. We will take a look at this debate by considering Ludwig Wittgenstein's distinction between the two uses of ' $\mathrm{I}$ ' as object and as subject and work out a further distinction within the subject-use of ' $I$ '. This relates to a problem that is inherent in Robert Brandom's inferentialist program regarding the role of first-personal vocabulary. It can be shown that subject-related aspects of language are necessary elements of inferentially articulated discourses-and not, like Brandom assumes, merely contingent features.
\end{abstract}

Keywords Expressivism $\cdot$ Self-consciousness $\cdot$ Inferentialism

1. In his Blue Book, Wittgenstein makes a remarkable and famous distinction between the object- and the subject-usage of first-personal pronouns. The object-usage occurs in phrases like "I am a father" or "My arm is broken". In such phrases we can always substitute the first-personal pronoun by a proper name without a change of meaning. Descriptions like these are always identifications of individuals which are embedded into empirical circumstances. In these descriptions the egological vocabulary is used just a proper name - and can, therefore, be substituted by it without loss of meaning. Due to this possibility of substitution, as a central characteristic the object-use of firstpersonal language is fallible. Of course, I can be mistaken whether it is really me who

Bastian Reichardt

bastian_reichardt@riseup.net

1 University of Leipzig, Leipzig, Germany 
is six feet tall or whether it is really $m y$ arm that is broken. However, in the subjectusage such errors are not possible. The subject-usage of "I" occurs in sentences like "I see a rabbit" or "I am in pain". In these cases, it is not possible to mis-identify me as the one who is seeing something or who is in pain. I do not need to recognize the pain and then observe whether this pain belongs to me or someone else-whereas, in the object-usage, I must recognize the broken arm and then predicate this empirical occurrence to myself. Therefore, it is not possible to be mistaken about the fact that it is $m e$ who is in pain (see Wittgenstein 1965: 66-67).

Wittgenstein assumes that the "immunity to error through mis-identification"- as Shoemaker (1968) later calls it-is dependent on the circumstance that the subjectusage of "I" is a non-referential, expressive way of speaking. The reason for this is that the subject-usage, unlike its objective counterpart, originates from its relation to so-called natural expressions. There is no essential difference between I-sentences in the subject-usage and unarticulated exclamations. Both-"I am in pain" as well as "Ouch!"- are rule-governed behavior; one in verbalized form and the other in merely vocalized form. Due to the respective training, both have substituted the original expression - like the face contorted with pain or the crying. So, the subjectusage of "I" stands in a certain relation to "natural expressions", as Wittgenstein calls them. The analysis shows that sentences in the subject-usage are expressive because - although they are not reducible to unarticulated exclamations - they are insofar coextensive in meaning as both, "I am in pain" as well as "Ouch!", have the same conditions of applicability. Whenever "Ouch!" can be meaningfully uttered, then it can be substituted by "I am in pain" without a change in meaning.

Based on Wittgenstein's distinction between object- and subject-usage of "I", William Alston and Ernst Tugendhat have tried to show that-despite this correct distinction-it would be false to say that expressive sentences could have no assertoric function (see Alston 1965 as well as Tugendhat 1979, Ch. 5). Alston expresses this point by showing that the relation between cognition and expression is not that of exclusion. Rather the respective utterances can be substituted by each other in our language-games: "I can express disgust at X just as well by saying 'I'm disgusted', as by saying 'How revolting', or 'Ugh'. I can express approval as well by saying 'I completely approve of what you are doing' as I can by saying 'Swell' or 'Good show'. ... This shows that expressing and asserting are not mutually exclusive in the way commonly supposed" (Alston 1965: 16).

2. If we take a closer look on the subject-usage of "I", we can make a further distinction which makes it possible to say that at least some utterances in the subject-usage are both, expressive and assertoric. In his remarks in the Blue Book, Wittgenstein is notoriously quiet about what it is that is expressed in the subjectusage of "I". By focusing on this question, we see that Wittgenstein's distinction stands in need of completion: There needs to be a further distinction within the subject-usage itself because different utterances in the subject-usage can express different stances. We will draw this further distinction by considering the sentences "I am in pain" and "I see a blue book".

In these two sentences, different attitudes are expressed. Both are cases of the subject-usage because it is not possible to err that it is me who is in pain or seeing a blue book, respectively. However, there is a difference of what is expressed. 
Utterances like "I am in pain", "I am bored", or "I am tired" express an aspect of my phenomenal "inner life". These are expressions of how I feel. And such expressive behavior can, accordingly, be called phenomenally-expressive. On the other side, there are utterances like "I see a blue book" or "I remember last summer" which are also part of the subject-usage, but which are not concerned with my emotional state. What is expressed in such sentences, is a small part of my system of beliefs. I am expressing my cognitive state towards an intentional correlate which is —unlike my pain or tiredness-independent from myself; the blue book or the last summer. In opposition to phenomenally-expressive I-sentences, we can call such expressive behavior epistemically-expressive I-sentences. ${ }^{1}$

Nevertheless, the distinction between these different subject-usages of "I" is only plausible if we have a clear and distinct criterion of demarcation at hand. And here it is: The distinction between epistemically-expressive and phenomenally-expressive I-sentences consists in the latter being able to be semantically substituted by nonverbal forms of expression. Without loss of meaning, utterances like "I am in pain" or "I am tired" can be substituted by the respective bodily, non-verbal expressionslike screaming or yawning. But for a sentence like "I remember last summer" there is no such non-verbal equivalent. It is a distinctively verbal expression.

However, this is not to say that there is a non-verbal equivalent for every phenomenally-expressive I-sentence. Surely, there are cases in which I might express a phenomenal aspect of my "inner life" in a solely corporeal manner for which we do not have a linguistic equivalent, simply because such expressions can be understood by every participant in ordinary discourse in an unproblematic way, i.e. for some original expressions there might be no need to acquire a linguistic counterpart (think, for instance, of existential angst). And on the other hand, there might be genuine linguistic kinds of expressions which do not have a solely corporeal counterpart. This extends Wittgenstein's idea that persons have acquired a new behavior of pain by saying "I am in pain" (instead of using the natural expression). The complex web of language might allow it that-in a phylogenetic perspective-persons proceeded from trained linguistic substitutes of original expressions to genuine linguistic expressions. ${ }^{2}$

The differentiation between phenomenally- and epistemically-expressive I-sentences also matches an observable distinction we are acquainted with from our lifeworld: A large part of the attitudes which are expressed in phenomenally-expressive I-sentences are attitudes that we share with other non-human forms of life. At least among mammals, we can say that there is a whole bunch of those non-verbal expressions that we have guised in the form of language: tiredness, pain, and (in parts) even grief. By verbalizing these attitudes, human animals have learned a new way to express themselves. However, epistemically-expressive I-sentences are due to their non-substitutability by non-verbal expressions a distinctively personal

\footnotetext{
${ }^{1}$ Bar-On (2004, pp. 4-5) has made a similar observation regarding I-sentences. She calls these sentences "attitudinal avowals". Yet, I have not made up my mind about the relation between Bar-On's attitudinal avowals and what I call "epistemically-expressive I-sentences".

2 In any case, I have to leave this problem undecided at this point because it would lead us to a whole new research project-from the question whether there are different forms of expression within the subject-usage of "I" to the question how those different forms of expression relate to one another.
} 
phenomenon. Because it is the system of beliefs that is expressed in such sentences, only persons can express themselves in this way.

3. We can further elucidate the relation between assertion and expression by applying the point Alston makes in his article quoted above: It is not just the case that assertion and expression are not mutually exclusive-they are clearly not. The problem rather stems from the fact that due to their possible assertoric force expressive utterances obviously can be embedded in cognitive discourse. Even phenomenally-expressive utterances like "I am tired" issue inference licences. From this utterance, I can draw the conclusion "So, I should go to bed". Even more: In what might be called a "pragmatic rejection of the problem of other minds", I can draw conclusions from your phenomenally-expressive I-sentences. ${ }^{3}$ If you are my guest and you utter "I am thirsty", then I will draw a conclusion from this which will (hopefully) lead me to do something: I serve you a drink. If we explain my action of giving you something to drink by claiming that I drew the conclusion that I might serve you a drink from your phenomenally-expressive utterance, then this is the best explanation for my behavior in this scene. Hence, even phenomenally-expressive I-sentences can be part of assertoric discourse-part of the game of giving and asking for reasons. Such utterances surely issue inference licences. However, in this article I want to focus on epistemically-expressive I-sentences because, otherwise, this would lead us too far afield. At the end, both phenomenally- as well as epistemically-expressive I-sentences lead to the same problem: How can we embed expressive language into our ordinary way of using reasons. ${ }^{4}$

Epistemically-expressive I-sentences break the strict opposition between the expressive and the cognitive: they are-as their grammatical analysis showsexpressive but they cannot be established beyond propositional structures. Epistemically-expressive I-sentences are assertoric without being cognitive. Although with this new category we have not yet established a continuum between the expressive and the cognitive, the strict distinction between those poles gets decisively washy.

As David Finkelstein correctly remarks: “...for Wittgenstein, an expression is, typically, the perceptible emergence of some psychological phenomenon (or phenomena) in a creature's doings" (Finkelstein 2010: 188). Now, the special doings we are concerned with are utterances-or more specifically: I-sentences. But how are these distinctive doings related to our capacity of carrying out rational discourses? What is the relation between rationality and the expression of selfconsciousness in the form of epistemically-expressive I-sentences? ${ }^{5}$ One way to re-

\footnotetext{
${ }^{3}$ By calling this a "pragmatic rejection", I do not mean that the problem of other minds is thereby solved. I think a big part of Wittgenstein's quietism stems from the fact that the problems of philosophy are not always problems we are acquainted with from our everyday life. In this sense, philosophical problems can be rejected by a "perspicuous representation" (see Wittgenstein 2009, §122) on what persons do in ordinary discourse instead of over-rationalizing our life-world. In such a "grammar of agency" most of philosophical problems would simply not occur.

4 Both, phenomenally- as well as epistemically-expressive I-sentences face what has come to be known as the "embedding problem" in metaethics. At the end of this paper I will come back to this point. The embedding problem has its origin in Geach (1965).

5 The question how a theory of self-consciousness can be embedded into the overall rational condition of a person is also addressed in Moran (2001: Ch. 3 \& 4).
} 
phrase this problem is to ask whether the linguistic expression of self-consciousness is a necessary element of our practice of giving and asking for reasons: If there are creatures like us - carrying out rational discourse-is it then necessary that firstpersonal vocabulary occurs in these discourses?

We can focus on an assumption in Robert Brandom's inferentialist program regarding the role of I-sentences. Brandom writes that "there need be nothing incoherent in descriptions of communities of judging and perceiving agents, attributing and undertaking propositionally contentful commitments, giving and asking for reasons, who do not yet have available the expressive resources ' $\mathrm{I}$ ' provides" (Brandom 1994: 559).

In how far agent-relative features of our discursive practices are recognized in Brandom's inferentialism is subject to an on-going debate since Mark Lance and Rebecca Kukla published their book >Yo! and >Lo! in (2009). Our discourses have agent-relative features if, and only if, for the normative status of an utterance (in Brandom's vocabulary: for the relations of commitment and entitlement) it is constitutive that it is me who is making this utterance. In other words: A discursive move is agent-relative if the normative status is dependent on the utterance being related to the epistemic position of a specific person (or logically dependent on this). Lance and Kukla criticize Brandom for assuming that his model of deontic scorekeeping is essentially impersonal.

They introduce two forms of speech acts to show that, in an inferentially articulated discourse, there must be room for agent-relativity. Those speech acts are recognitives and-as a sub-class of those-observatives. To give a short characterization of those speech acts, we can consider the following quotes from Lance and Kukla:

recognitives:

....any speech act a function of which is to give expression to a speaker's recognition of something. ...the pragmatic function of the recognitive is to discursively mark and communicate the event of recognition itself (2009: 46). observatives:

...are those recognitives that give expression to our recognition of an empirical fact, object, or state of affairs in observation, and most paradigmatically in perception" (2009: 46) "Observatives—unlike declaratives—do not issue reassertion licences (2009: 48).

How do the kind of avowals outlined above-epistemically-expressive I-sentencesrelate to those speech acts? First and foremost, they share the same fundamental idea, namely that there is a distinctively first-personal element in our discourses. Furthermore, epistemically-expressive I-sentences share the pragmatic function of recognitives-i.e. giving expression to my recognition of something independent from myself. However, there is a crucial difference: epistemically-expressive I-sentences are not observatives, for at least two reasons: (1) As said above, this expressive behavior issues inference licences. Following Alston, we assume that expression and assertion are not mutually exclusive. Therefore, epistemicallyexpressive I-sentences can be considered as assertions. (2) The scope of observatives is restricted to the recognition of the empirical world in observation. Epistemically- 
expressive I-sentences extend this scope. Although we have used "I see a blue book" as paradigm case for epistemically-expressive I-sentences, avowals are not restricted to observation. We have distinguished epistemically-expressive I-sentences from their phenomenally-expressive relatives by pointing out that I express my epistemic relation to an intentional correlate that is independent from myself. This intentional correlate can be an empirical thing (like the blue book) but it can also be anything else: something that existed in the past and is, therefore, not observable (like the last summer), or a fact that is not represented in the empirical world at all (like a mathematical truth), or even something purely fictional (like Peter Pan).

Epistemically-expressive I-sentences relate me epistemically to something else. This epistemic relation is not restricted to observation. So, we can say that these avowals encompass a wide range of I-sentences:

I see a blue book

I remember last summer

I know that $\pi>3$

I am thinking about Peter Pan

All of those sentences are recognitives but only the first one might count as observative. The upshot is: Epistemically-expressive I-sentences are not declaratives because the first-personal pronoun is not used like a proper name. But they are also not observatives because they extend their scope by issuing inference licences and because they are not restricted to empirical observation. What this kind of speech act does, is asserting $m y$ logical position in the space of reasons. At the same time, because this speech act issues inference licences it is providing me with a range of entitlements and commitments. How we can understand the term "logical position", will be shown below when we implement this kind of speech act into the project of Inferentialism in $\$ 4$.

Furthermore, Lance' and Kukla's objection against Brandom goes even deeper: They claim that Brandom over-rationalizes our discursive practice. According to them, Brandom sees the autonomy of discourses in such a strong way that he is lead to the assumption that it is only a contingent feature of our discourses that they are carried out by creatures like us, i.e. persons who are engaged in the world with their perceptions and their actions. Following Sellars, to Brandom perceptions and actions are merely language entry- and exit-transitions. For the normative status of inferentially articulated assertions they do not play an essential role. The discourse, we might say, is what happens between perception and action.

Essentially, Lance' and Kukla's criticism consists in the claim that a practice of inferentially articulated discourse must be carried out by embodied agents. ${ }^{6}$ In what

\footnotetext{
${ }^{6}$ Lance and Kukla have introduced the notion of voice to say that there must be room for the fact that our discourses are carried out by persons with material bodies: "We argue that it is only concretely located agents that can have a first-person perspective or voice. Furthermore, we claim that there must be room for such first-person perspectives within a theoretical account of discursive practice, in order for it to successfully make sense of meaning, discourse, or normative statuses. Brandom's abstract normative pragmatics, we claim, does not have the theoretical resources for identifying such perspectives, and hence it needs substantial enrichment before it can accomplish what it seeks to accomplish" (Lance and Kukla 2010: 116).
} 
follows, we will extend this criticism by showing that the creatures pursuing rational discourse are not only embodied agents but also that the non-indexical first-personal vocabulary-i.e. the subject-use of "I"-is a necessary device in inferentially articulated discourses.

To do so, we can concentrate on a related objection to Brandom's view on firstpersonal utterances that goes, however, in a slightly different direction. The argument is that Brandom needs to make room for agent-relative features in his inferentialism because otherwise his view on the logical role of "I" contradicts one of the central elements of his own inferentialist program. Such an objection was brought about by Levine (2009).

4. An essential component of the inferentialist project in Brandom's work is that the entitlement of a speaker to an assertion can be challenged by other persons. If a speaker is committed to an assertion, then entitlement to this assertion is also ascribed to her-by default. If you are committed to claim that $\mathrm{p}$ is the case, then you are also entitled to claim that $\mathrm{p}$ is the case. However, whether a speaker is entitled to claim something is not cast in stone but can be questioned. Levine points out that this fundamental structure of inferentialism-which Brandom calls the default and challenge structure of entitlement-implies that first-personal utterances are a constitutive element of the game of giving and asking for reasons-and not, like Brandom claims, an optional addition. According to Levine, the agentneutrality of discourses-i.e. the optional character of the word "I"-cannot be maintained if it is necessary for the entitlement to an assertion that it is derived from the epistemic state of a person. In other words: If a person is only entitled to an assertion because this assertion stands in a logical relation to something over which the person has epistemic authority, then a discourse is agent-relative.

It is not difficult to think of everyday examples in which someone's entitlements are dependent on epistemic states over which only she has authority. Annie, for instance, might be entitled to claim that John is probably not hungry because she has seen him eating a pizza half an hour ago. Of course, the fact that someone has eaten a pizza moments ago suffices to draw the conclusion that this person is probably not hungry anymore. And this is the position Annie is in: She has seen John eating and is justified to draw her conclusion based on a common fact. Let us make this example more general: We assume that I am entitled to claim that B is the case because I have perceived A and because it is true that B is always the case when A is the case. Now, if you doubt whether I am entitled to claim "B", then I will justify my entitlement by saying that I have perceived A. The important point is that I am not justifying my entitlement to "B" by saying "A is the case" but rather by saying "I have perceived A". And this means that the first-personal pronoun is not an optional element of my justification. For my entitlement to claim "B" it is necessary. The logical origin of my entitlement to claim " $\mathrm{B}$ " is neither my acknowledgement of "A F B" nor my commitment to "A". Since I am only committed to "A" because of the truth of "I perceive A", my entitlement springs from my first-personal expression. We can describe my entitlement to "B" also as a situation in which I am committed not to deny "B". Greg Restall frames this as, what might be called, a logico-pragmatic position which I cannot reach in discourse if I commit myself to the rules of rationality - a position which consists of an entanglement of the notions 
of "assertion" and "denial" in the following way: "If $\mathrm{A} \vdash \mathrm{B}$, then the position consisting of asserting 'A' and denying 'B' clashes" (Restall 2012: 82). ${ }^{7}$ Or to reformulate this idea in a positive way: Because I have perceived A, I am in a position of entitlement to assert both ' $\mathrm{A}$ ' and ' $\mathrm{B}$ '. In this situation, the default and challenge structure of entitlement must allow it for you to challenge my entitlement to " $\mathrm{B}$ " by going back to its logical origin-i.e. this fundamental element of Inferentialism must allow you to challenge my position in the space of reasons. And there we see that my entitlement builds upon the use of the first-person pronoun. The question we now face is whether this use of the first-person pronoun is irreducible?

Levine concludes that Brandom can only ensure the consistency of his argumentation if he assumes that the default and challenge structure of entitlement is not an essential characteristic of his inferentialist program. However, inferentialism would then contain dogmatic elements because some entitlements could not be challenged at all. Yet, this conclusion is a bit too hasty. Brandom could repel Levine's objection if he adopts Wittgenstein's distinction between subject- and object-usage of "I". I-Sentences in the object-usage are agent-neutral in Brandom's sense because the first-personal pronoun is used like a proper name. And utterances in the subject-usage (like "I perceive A") are no assertions at all and, hence, cannot play a significant role in the game of giving and asking for reasons. On this basis, Brandom can repel Levine's objection: I-sentences either can be substituted by their proper name-equivalent or they have no assertoric function and are, therefore, not part of the space of reasons. As Brandom makes clear in the eighth chapter of Making it Explicit, he assumes that "I" is an indexical notion which always marks an object that covers a continuous path in empirical space. So, "I" in Brandom's sense matches the object-usage. Every instance of the subject-usage can be rejected with the remark that this is not an example of assertoric language-and, accordingly, nothing that finds its expression in our deontic score-keeping. Following this line of thought, the use of the first-person pronoun would either be reducible to talk of proper names instead of using the word "I" or be not part of rational discourse.

However, if our further distinction of the subject-usage is correct, then Brandom's assumption that I-sentences are optional elements of our discursive practice is untenable-or better: this assumption is incompatible with his own program.

If the sentence "I perceive A" is an epistemically-expressive I-sentence, then this sentence plays an assertoric role and can, therefore, be considered a part of our reasoning. In this case, the first-personal pronoun cannot be substituted by a proper name because "I perceive A" is-being an epistemically-expressive I-sentence-the subject-usage of "I". "N.N. perceives A" simply does not mean the same as "I perceive A" because the word "I" is not used like a proper name. Of course, here you can still question whether I really perceived A and not something else. But this does not matter. The important point is that it is me who is perceiving A or

\footnotetext{
7 The description of the relation of "assertion" and "denial" as a position is embedded into a broader program in Restall's work in which he assumes that the denial of "p" cannot be analyzed as " $\neg$ ". Restall argues that "denial" is a more basic concept than "negation" (see Restall 2005).
} 
something else and that the first-person utterance is necessary to justify my entitlement to assert "B".

Levine's objection is a step in the right direction but only with the distinction between phenomenally- and epistemically-expressive I-sentences the argument can be fully carried out. Now we can say that the logico-pragmatic position (defined in the quote from Restall above) is, exclusively, my position because the truth of "A" (from which "B" can be derived) is solely provided by the truth of "I perceive A"i.e. this position in the space of reasons only occurs because of my epistemicallyexpressive I-sentence. Due to the default and challenge structure of entitlement, epistemically-expressive I-sentences must be considered as constitutive elements of the game of giving and asking for reasons.

Epistemically-expressive I-sentences express a little part of a person's system of beliefs by relating the speaker to an intentional correlate which is independent of herself. Interestingly, all utterances concerning our own perceptions-utterances of the form "I see/smell/hear etc. X"-are epistemically-expressive I-sentences in this sense. According to Brandom, perceptions are merely language entry-transitions and, as such, irrelevant to the normative status of inferentially articulated assertions. This was, as said above, what Lance and Kukla criticized. ${ }^{8}$ Here we see now that the linguistic expression of my own perception-and, hence, mediately my perception itself - is essentially bound to other assertions in our discourses. So, it might be necessary for Brandom to say that the creatures which are discursively active must be creatures like us-i.e. embodied persons which experience the world through their senses. In how far this would undermine Brandom's explicitly rationalist paradigm is a question that would take us too far afield now.

Another serious problem that occurs at this point is: How do we handle the fact that epistemically-expressive I-sentences - as expressive utterances-have no truthvalue? Epistemically-expressive I-sentences are constitutive elements of the game of giving and asking for reasons, but they are not cognitive elements of language. How can something that is, strictly speaking, not true or false be a constitutive element of inferentially articulated discourses? What is needed here, is an instrument which can reconstruct the inferential relations between cognitive and expressive utterances - an expressive logic. However, if such a project is doomed to failure in principle then one of the following two things must be true: Either there is a deep inconsistency in Brandom's program, because the game of giving and asking for reasons would make use of resources which are not within the space of reasons, or everything I have written in this paper is false.

Open Access This article is licensed under a Creative Commons Attribution 4.0 International License, which permits use, sharing, adaptation, distribution and reproduction in any medium or format, as long as you give appropriate credit to the original author(s) and the source, provide a link to the Creative Commons licence, and indicate if changes were made. The images or other third party material in this

\footnotetext{
${ }^{8}$ In their discussion of observatives, Lance and Kukla make the point as follows:»To perceive, then-as opposed to just inheriting entitlement to a belief-is to be first-personally claimed by what I see. To express this first-personal episode in language is to take on a singular responsibility for correct observation in a way that is not an expression of any kind of shared, agent-neutral commitment « (2009: 49).
} 
article are included in the article's Creative Commons licence, unless indicated otherwise in a credit line to the material. If material is not included in the article's Creative Commons licence and your intended use is not permitted by statutory regulation or exceeds the permitted use, you will need to obtain permission directly from the copyright holder. To view a copy of this licence, visit http:// creativecommons.org/licenses/by/4.0/.

\section{References}

Alston, W. (1965). Expressing. In M. Black (Ed.), Philosophy in America (pp. 15-34). Ithaca: Cornell University Press.

Bar-On, D. (2004). Speaking my mind: Expression and self-knowledge. Oxford: Clarendon Press.

Brandom, R. (1994). Making it explicit. Reasoning, representing, and discursive commitment. Cambridge, MA: Harvard University Press.

Finkelstein, D. (2010). Expression and avowal. In K. D. Jolley (Ed.), Wittgenstein: Key concepts (pp. 185198). Cambridge: Cambridge University Press.

Geach, P. (1965). Assertion. Philosophical Review, 74, 449-465.

Lance, M., \& Kukla, R. (2009). ,Yo!ı and ,Lo!r. The pragmatic topography of the space of reasons. Cambridge, MA: Harvard University Press.

Lance, M., \& Kukla, R. (2010). Perception, language, and the first person. In B. Weiss \& J. Wanderer (Eds.), Reading Brandom: On making it explicit (pp. 115-128). London: Routledge.

Levine, S. (2009). Expressivism and I-beliefs in Brandom's 'making it explicit'. International Journal of Philosophical Studies, 17, 95-114.

Moran, R. (2001). Authority and estrangement: An essay on self-knowledge. Princeton: Princeton University Press.

Restall, G. (2005). Multiple conclusions. In P. Hajek, L. Valdes-Villanueva, \& D. Westerstahl (Eds.), Logic, methodology and the philosophy of science: Proceedings of the twelfth international congress (pp. 189-205). London: King's College Publications.

Restall, G. (2012). Assertion, denial and non-classical theories. In K. Tanaka, F. Berto, E. Mares, \& F. Paoli (Eds.), Paraconsistency: Logic and applications (pp. 81-99). Dordrecht: Springer.

Shoemaker, S. (1968). Self-reference and self-awareness. Journal of Philosophy, 65, 555-567.

Tugendhat, E. (1979). Selbstbewußtsein und Selbstbestimmung. Frankfurt/Main: Suhrkamp.

Wittgenstein, L. (1965). The blue and the brown books. New York: Harper-Perennial.

Wittgenstein, L. (2009). Philosophical investigations. Revised 4th edition by P.M.S. Hacker and J. Schulte. Oxford: Wiley Blackwell.

\section{Publisher's Note}

Springer Nature remains neutral with regard to jurisdictional claims in published maps and institutional affiliations. 